\title{
THE QUESTION OF QUESTIONS IN MALAYSIAN ENGLISH
}

\author{
Radina Mohamad Deli ${ }^{1}$ \\ Asniah Alias ${ }^{2}$ \\ ${ }^{1}$ Centre for Language Studies, Universiti Malaysia Sarawak \\ ${ }^{2}$ Language Center, National Defense University of Malaysia \\ 1mdradina@cls.unimas.my \\ ªsniah@upnm.edu.my
}

\begin{abstract}
This paper examined the forms that interrogatives and tag questions can take when used by young Malaysian speakers of English language in oral communication. It offers a description of the features for both question forms as produced by the respondents compared to those of Singapore English (SE) and Standard British English (SBE). The influence of domains and the issue of mother tongue interference in relation to the subjects' usage of such features will also be investigated. Data were obtained through interviews with 19 Malaysian English (ME) speakers from three major ethnic groups in Peninsular Malaysia and via the recording of six conversations. The results showed various distinctive forms and features of questions in ME used by the speakers. Their usage is found to have a certain link to the domains of conversation. Further analysis revealed that mother tongue interference at the grammatical level, particularly in the case of Malay and Cantonese, plays a major role in determining the structure of ME interrogatives and tag questions as well as the subjects' unvarying use of the rising intonation as regards the latter. As a result of this interference, ME tag questions used are found to be confined to four forms whilst both the structure of wh- and polar interrogatives experience reduction in the system of tense, auxiliary and operator when used by the subjects.
\end{abstract}

Keywords: interrogatives, tag questions, mother tongue interference, Malaysian English, Singaporean English

\section{Introduction}

Is there any one form of English language that is better than the others? This is indeed a tricky question considering the fact that there are a variety of English actively and practically used across the globe. With the rise of English as a global language, it is only natural that English-speaking countries could no longer claim ownership of the language as local varieties blossom and continue to thrive (Halliday, 
Maclntosh, \& Strevens, 1964). Such a localisation often affects countries which were once colonised, and Malaysia is not an exception. This form of English language is commonly known as Malaysian English (ME) (Baskaran, 1994; Pillai, 2006) or Manglish (Lee, 1998). The former is typically used as a general term to refer to all sub-varieties of the English language used by Malaysian speakers whilst the latter is often associated with the colloquial version of the language. For this particular study, the term ME is used to refer to a more colloquial form of the language. It is evident that the existence of a multitude of languages spoken by the locals has largely influenced the English language spoken in the country.

In terms of question formation, the variety of ME varies from the norm of question formation in Standard British English (SBE) (Baskaran, 1994). Much of the ME grammatical structures particularly for interrogatives, similar to Singapore English (SE), also known as Singapore Colloquial English (SCE), are claimed to be influenced by either Chinese or Malay, the dominant national language, or both (e.g., Cole \& Herman, 1998; Gupta, 1994; Kow, 1995; Low \& Brown, 2005; Sato, 2011). How questions are formed in the English language have thus become a common source of linguistic investigation for many scholars who investigated how or how much second or foreign language speakers have attained or acquired nativelike speech or language use. Intricate and complicated ways of forming questions in the English language commands extra linguistic ability in second and foreign language speakers. Consequently, errors are common in non-native speech or written data. Ting, Mahanita, and Chang (2010) found questions to be the second most frequent grammatical error among the five common ones made by less proficient learners of English in a speaking task for a subject at a Malaysian university. In South East Asia, studies of interrogatives of local Englishes are also popular (Alsagoff, Bao, \& Wee, 1998; Borlongan, 2008).

There are many ways of asking questions in English. A rising intonation on a declarative may be used to ask a question (e.g., You knew him?). This is common in the case of SE where tentative particles especially $a h$, hah, and hor, too are also used to show questions (Gupta, 1994). As SE's grammatical features are usually akin to those of $M E$, it is easier to identify the ME interrogatives forms used by the subjects of this study and understand how the forms work based on SE. However, in order to make a valid comparison between those produced by the subjects and those of SBE, this study will focus on the forms of interrogatives and tag questions in ME.

Constructing an interrogative in SBE is extremely complex, as it generally involves inversion of the subject and the verb. Moreover, except for a handful of verbs (be, have, do and modal auxiliaries), an appropriate part of the verb do must be inserted in order to invert (e.g., Did you leave the door open?). In SE, do-insertion is not used at all. In ME, interrogative clauses typically disregard subject-operator inversion (Baskaran, 1987). Thus, it can be said that in SE and ME, interrogatives are much less complex than they are in SBE. The patterns of making interrogatives in SCE, as asserted by Gupta (1994), have been influenced by both Chinese and Malay, but are, incidentally also less complex than interrogatives in these two languages. Crewe (1979) has also mentioned something similar when he stated that due to the interference of the Chinese or Malay construction, the verb to be as well as other 
auxiliary verbs is frequently omitted from a (declarative) sentence. The analysis on ME interrogatives will also include a discussion on the structure of Malay and Cantonese interrogatives in relation to the formation of interrogatives in ME, based on the works done by Kader (1981), Asmah Haji Omar (1993) and Cheung (1974). The discussion on the interference of the subjects' mother tongues' question structure is done on the basis of Mackey's (1970, p. 569) neutral definition of it as "the use of features belonging to one language while speaking or writing another", as there is no reference to norm or deviation in the definition.

The tag question, as mentioned previously, is another form of question highlighted in this study. Tag questions are questions that are tagged onto the end of a declarative sentence as in Jason plays the guitar, doesn't he?, which consist of a main or auxiliary verb followed by a pronoun or existential there. The choice of auxiliary, pronoun and tense depends on the forms in the clause (Leech \& Svartvik as cited in Norrizan Razali, 1995). In speech, the falling and rising intonation of a tag indicates different meanings. Malaysian speakers, as asserted by Platt and Weber (1980) and Norrizan Razali (1995), are not aware of the different purposes served by the different intonations, that they tend to only use the rising intonation.

In regard to the forms of tag questions, most languages have one standardised form such as n'est-ce pas? in French, nicht wahr? in German and bukan? in Malay, as stated by Crewe (1979). ME almost achieves the same kind of unvarying tag question form by using only four forms of tag questions, right?, ah?, is it?, and isn't it? after any statement, whereas SBE uses the complicated procedure of repeating the verbal auxiliary and reversing the positiveness or negativeness of the sentence. The ME speakers' tags, as asserted by Norrizan Razali (1995), are confined to these four forms. For two of the four forms, namely, is it? and isn't it?, Gupta (1994) stated that in SCE, they are examples of inversion because they do not change according to the auxiliary in the preceding clause. Consistent with Gupta's claim, several earlier studies have also shown that the features of ME tag questions deviate from the form in SBE. In addition, Wong (1983, p. 135) states and asserts that the tag questions of colloquial ME are a "vastly reduced system" in that the tags isn't it? and is it? are used "almost interchangeably" regardless of the grammatical features of the preceding sentences. Based on the previous findings, this study attempts to identify and describe the features of tag questions used by a group of young Malaysians.

Subsequently, this study will investigate the relationship between the structure and the formation of questions in Malay, Cantonese, and Tamil (the subjects' mother tongues) with that of ME and SBE mainly involving works by Kader (1981) and Cheung (1974) - based on a study done by Kow (1995). Kader (1981) states that in Malay, a tag question is made up of a declarative sentence and a tag bukan (not) in sentence final position. The declarative sentence may be in the positive or negative but there is no reversal of polarity:

Liza (tidak) pergi ke sekolah kelmarin, kan (bukan)?

Liza (not) go to school yesterday, not? 
Similarly in Cantonese, a tag question is formed from a declarative sentence and a tag ah (particle) at the sentence end. The tag question may be of either polarity, and similar to Malay, there need not be any reversals (Cheung, 1974):

Ngohdeih heui tai hei hou mh hou ah?

We go see movies good (neg.) good? (particle)

Bearing in mind the results of previous studies in the field, this study specifically investigates (1) how interrogatives and tag questions in Malaysian English are formed in the speech of young adults; and (2) whether domains and language interference or not play a role in determining question formation.

\section{Methodology}

Two types of method were used for the purpose of data collection, namely, recording of conversation and interview. For the recording, a tape recorder was used in order to record six conversations, two of which are radio conversations whilst the rest were casual in nature:

- Conversation 1 - interaction between two friends

- Conversation 2 - interaction between two housemates

- Conversation 3 - interaction between two friends

- Conversation 4 - interaction between two roommates

- Conversation 5 - radio talk show

- Conversation 6 - radio talk show

Contrary to the radio conversations, the everyday conversations were recorded with the subjects' knowledge. These conversations were later transcribed and all the grammatical features were highlighted.

The interviews, on the other hand, were done in face-to-face sessions with the subjects, where answers were written down by the researcher there and then. $A$ set of four questions - which includes translation tasks was prepared earlier and utilised during the sessions. Questions 1 and 2 cover subjects' attitude and selfperception towards the usage of question forms in English. Questions 3 and 4 involving translation tasks are as follows:

- Is there any connection between these question forms (interrogatives and question tags) and the ones used in your mother tongue (Malay/Chinese/Tamil)?

- Translate one of the first three pairs of sentences (according to your mother tongue) into English and the last three sentences into your respective mother tongues:

Semalam awak jumpa dia kan?

Hari ni Mira tak datang tak?

Naan alaga ille? 
Anthe "car" alaga irukku ille?

Ngohdeih heui tai hei hou mh hou ah?

Neih mh haih behng ah?

Where did he eat?

Where does he eat?

Where is he eating?

The subjects for the study consisted of 19 students, aged 21 to 25 , from the Faculty of Modern Language and Communication, Universiti Putra Malaysia, who were either majoring in English Language or Broadcasting. The students were selected from the three major ethnic groups in Peninsular Malaysia: 7 Malay, 4 Chinese, and 8 Indian subjects. The breakdown by gender is shown in Table 1 . The data gathered were analysed and reported using frequency and percentage.

Table 1

Total number of subjects according to race and gender

\begin{tabular}{llll}
\hline Race & Female & Male & Total \\
\hline Malay & 7 & 0 & 7 \\
\hline Chinese & 1 & 3 & 4 \\
\hline Indian & 6 & 2 & 8 \\
\hline Total & 14 & 5 & 19 \\
\hline
\end{tabular}

\section{Results and Discussion}

The analysis of the subjects' oral interactions reveals several forms that interrogatives and question tags can take when used by a group of Malaysian speakers, as follows:

\section{Wh-interrogatives}

The omission of auxiliaries (the verb be, do) in questions requires inversion of the subject and auxiliary (questions in which the target is not the subject of the sentences) such as:

How many you smoke a week?

How you like working there?

What he work as?

\section{Yes/no interrogatives}

The omission of either operators (auxiliaries and modals) or the do-operator at the beginning of the sentences. For instance;

You think the framing shop will be open ah? 
You give her the card already?

Similarly, Govindan and Pillai (2009) found that the omission of auxiliary was common in non-standard forms (i.e., MCE) yes-no questions starting with has/have like the second example given earlier.

\section{Question Tags}

The is it/isn't it tags, the particle $a h$ and the form right in tag questions were used instead of appropriate auxiliaries when responding to the first one in the clause. For example;

To confirm:

They don't give you money, isn't it?

Your boss is ok with you, right?

\section{Genuine questions:}

You don't want your mom to step in, is it?

There's no big car, is it?

Nice ah?

He doesn't have any friends ah?

The resulting four types of tag questions produced by the respondents of this study correspond with Norrizan Razali's (1995) findings. The use of is it or isn't it is also found to be very common in question tags, most of which are non-agreeing in nature as in We are going, isn't it? (Baskaran, 2004). Govindan and Pillai (2009) found the frequent use of right to end tag questions in the speech of young Malaysian Indian speakers of English in informal setting followed by other particles and phrases such as $a h$ and isn't it respectively.

\section{The phrase or not}

The phrase or not was used to offer another contradicting alternative response from the first clause in an interrogative. Referring to the third example below, an observation on the modal can used reveals that in colloquial ME the modal takes a variety of functions including "to mean affirmation" (Wong, 1983, p. 137).
Alone or what?
With the family or what?
Can hear or not?
You know how hot it is or not?
You want to send them off or not?

Govindan and Pillai (2009) found three particles frequently used in non-standard forms of yes-no questions beginning with has/have are ah, or not and or what. It was further stated that or not may have come about due to the influence of the 
phrase ke tidak? in spoken Malay. This is a common strategy used to signify a question form. For example,

\section{Sudah pergi ke tidak?}

Already went or not?

5. Localised phrases in question form (direct translation of Malay, Chinese and Tamil phrases).

These localised phrases in question form are a direct translation of Malay, Chinese and Tamil phrases, for example,

For what?

Buat apa?

Where got?

Mana ada?

What to do?

Apa nak buat?

\section{Inclusion of fillers or particles such as ah and lah at the end of questions}

The inclusion of fillers or particles such as $a h$ and $l a h$ at the end of questions for emphasis. As stated by Wong (1983), fillers, though communicating no particular denotative meaning, are used to indicate emotive, effective attitudes on the part of the speaker. It is quite noticeable, for example, that the particle or filler which may be transcribed as either $a h$ and $a a$ is most frequently associated with a question in colloquial ME.

How was your course in P.D lah?

What did you do lah?

How come you don't know how to write memos ah?

Table 2 displays the total number of occurrences of each form of ME interrogatives and tag questions used in six conversations. Wh-interrogatives and tag questions had the highest frequency of occurrence (59 and 28 respectively). The sum for all ME question forms in each conversation suggests a relationship between their usage and the conversational domains in which they occur as well as the subjects' level of familiarity and intimacy with each other. With regard to the conversational domains, the friendship domain comprising Conversations 1, 2, 3 and 4 was found to contain more ME forms of interrogatives and tag questions than the talk show domain (Conversations 5 and 6) probably due to the more formal and controlled setting of the former which restricts the subjects' language use to preferably SBE. In line with the formal setting, the low level of familiarity and intimacy between the subjects (i.e., announcers and guests) play a major role in 
contributing to this scarcity of usage. Data from the friendship domain, however, suggest otherwise. Conversation 3, an interaction between two close (childhood) friends contained the highest number of occurrences with 33 , followed by Conversation 2, between two housemates, Conversation 4, between two roommates and Conversation 1, between friends, with 21, 19, and 18 occurrences respectively.

Table 2

Number of occurrences of each feature in six conversations

\begin{tabular}{|c|c|c|c|c|c|c|c|}
\hline \multirow[b]{2}{*}{ Question feature } & \multicolumn{6}{|c|}{ Conversation } & \multirow[b]{2}{*}{ Total } \\
\hline & 1 & 2 & 3 & 4 & 5 & 6 & \\
\hline Tag question & 9 & 14 & 15 & 9 & 6 & 6 & 59 \\
\hline $\begin{array}{l}\text { Wh-interrogative } \\
\text { (-Aux) }\end{array}$ & 5 & 8 & 9 & 4 & 1 & 1 & 28 \\
\hline $\begin{array}{l}\text { Polar interrogative } \\
\text { (-Ops) }\end{array}$ & 1 & 2 & 2 & 2 & 1 & 2 & 10 \\
\hline 'Or not' usage & 1 & 2 & 3 & 0 & 0 & 0 & 6 \\
\hline Questions (+ particles) & 2 & 1 & 3 & 0 & 0 & 0 & 6 \\
\hline Localised phrases & 0 & 1 & 1 & 4 & 0 & 0 & 6 \\
\hline Total (per conversation) & 18 & 28 & 33 & 19 & 8 & 9 & 115 \\
\hline
\end{tabular}

The ME wh-interrogatives and tag questions were further analysed to identify the use of ME form versus SBE form (Table 3 ) on the basis of their prospects and reliability as commonly-occurring features in ME question forms.

Table 3

Percentage of occurrences of ME wh-interrogatives and tag questions in each conversation

\begin{tabular}{lcccc}
\hline \multirow{2}{*}{ Conversation } & \multicolumn{2}{c}{ Wh-Interrogatives (ME) } & \multicolumn{2}{c}{ Tag Questions (ME) } \\
\cline { 2 - 5 } & Total & Percentage & Total & Percentage \\
\hline 1 & 5 & 45.5 & 9 & 100 \\
2 & 8 & 57.1 & 14 & 100 \\
3 & 9 & 75 & 15 & 100 \\
4 & 1 & 44.4 & 6 & 100 \\
5 & 4 & 11.1 & 9 & 85.7 \\
6 & 1 & 25 & 6 & 85.7 \\
\hline \multicolumn{5}{c}{} \\
\hline
\end{tabular}

Table 3 shows that none of the subjects used the SBE forms for tag questions for the casual interactions (Conversations 1 to 4 ) - all the tag questions with in the ME form. For the radio talk show (Conversations 5 and 6 ), $85.7 \%$ of tag questions were in the ME form. The difference in prevalence is due to the different levels of familiarity with each other and formality of the setting. The same pattern is shown for wh-interrogatives because the ME form was used frequently in the casual interactions than in the radio talk shows. 
Table 4

Frequency of different types of ME tag questions

\begin{tabular}{llc}
\hline Tag question & Examples & Frequency \\
\hline Right? & They did it purposely, right? & 30 \\
Ah? & He doesn't have friends, ah? & 16 \\
Is it? & You don't want your mom to step in, is it? & 7 \\
Isn't it? & At least you've got floor space, isn't it? & 6 \\
\hline & Total & 59 \\
\hline
\end{tabular}

As shown in Table 4, the form right? occurred the most frequently (30 out of the 59 tag questions). This is followed by $a h$, is it?, and isn't it $(16,7$ and 6 occurrences respectively). This concurs with findings by Govindan and Pillai (2009) for both negative and positive tags ending with right which made up approximately $70 \%$ of the responses respectively.

Furthermore, the analysis revealed that the tag questions deviated from SBE form. First, the tags were used with disregard for the grammatical features of the preceding clauses. The verb phrase of the preceding clause did in the first example is contradicted by the tag right that follows it. This form, similarly used in the rest of the examples, indubitably defies that of the SBE. Second, the negative or positive form of the tags does not comply with the rules for the formation of the SBE pattern (e.g., the use of double negative). Whilst the SBE maintains that when the preceding clause is positive, the tag has to be negative and vice versa. Third, the form right and particle ah were prevalently used by the subjects to form tag questions. In the case of the latter, its use clearly serves the function of a tag question as derived from its final position and the rising intonation complementing it - a form unknown to the SBE forms. Fourth, the pronoun form of the verb phrase in the tags, it, is the only pronoun found in all of the tags collected - which were used resoundingly without any recognition given to the subject of the previous clause.

Besides grammatical features, the tag questions used by the subjects also differed from SBE in the intonation. The functions of the rising and falling intonations in tag questions were also ignored by the subjects of this study in that they used only the rising intonation for all their tag questions. Platt and Weber (1980) had observed that Malaysian speakers of English are generally nescient of the fact that the rising and falling intonation of tag questions indicate different interpretations. The rising intonation was consistently used by the subjects to suggest different functions, namely, asking for confirmation, initiating a conversation, and asking a genuine question. 
Your room is twice the size of mine, right? You have heard about the accident right? All these people are communicating in silence, isn't it? technique
- To confirm

- Genuine question

Conversational

The different functions of the tag questions were obtained from the contexts in which they occurred, with all the four forms of tags being consistently accompanied by the rising intonation. Hence, the rising intonation cuts across all forms of tags used by the subjects to serve a universal function, as asserted by Norrizan Razali (1995).

As a conclusion, the deviant forms of tag questions as collected from the subjects can be divided into four types of violation of the SBE forms:

1. The verb phrase of the tag conflicts the verb phrase in the main clause.

2. The negligence of the SBE polarity rule for determining the negative or positive form of the tag's verb phrase.

3. An additional particle $a h$ borrowed from Chinese dialects - in this case, Cantonese as well as the form right functioning as tag questions.

4. A tag question of varying intentions signaled by the rising intonation, with no trace of any falling intonation.

The form right is found to occur overwhelmingly over the other forms, followed by the particle $a h$, is it and isn't it. This corroborates with Norrizan Razali's (1995) claim that the Malaysian English speakers' tags are confined to four forms as mentioned earlier, although Platt and Weber (1980), and Kow (1995) contend that the tags are confined to either only one or two forms, is it? and isn't it?. This finding may suggest that right? is more prominently used by ME speakers than is it? which is often deemed as a prevalent all-purpose universal question tag (Lim, 2009).

With regard to the omission of auxiliaries, the verb be and do, for instance, in wh-questions or interrogatives which require inversion of subject and auxiliary (questions in which the target is not the subject of the sentences), it is evident that the formation of interrogatives in ME has violated the rules of formation of SBE. Reduction refers to what has been left out of the system, for example, the tense system of SBE. Linked to the usual reduction in the system of tense and aspect is the reduction in the modal auxiliary system in colloquial ME (Wong, 1983). Ting et al. (2010) also highlighted the omission of auxiliary in questions as a frequent error made by less proficient students, accounting for almost $70 \%$ of total question errors. This tendency to omit verbs and auxiliaries is not only true for interrogatives but also declaratives as stated by Crewe (1979), in the case of SCE. It is also true in the case of ME yes/no interrogatives. Additionally, in SBE, either Operator + subject + rest of verb or a do-operator insertion (if there is no auxiliary in the verb in the declarative) provide an interrogative form for questions requiring the answer Yes or No as opposed to the ME way of forming polar (yes/no) interrogatives, with its omission of operator, opting for the simpler subject + rest of verb form (e.g., You give already?). The reduction in the SBE systems is easily observed in the subjects' question 
formation. For instance, in the sentences when (is) the seminar? and what (do) you expect?.

The data obtained from the subjects' responses to interview questions 3 and 4 (see Methodology section) revealed mother tongue influence in the ME forms of questions. All the subjects consider the forms of questions to have a certain connection with the ones used in their mother tongue - particularly in terms of tenses in wh-interrogatives and the usage of the particle $a h$ as a tag question. The first pair in question 4 consist of the words kan and tak - which are the abbreviated forms of the Malay words bukan and tidak respectively, that function as tag questions, whilst the last pair in Cantonese were formed using the particle ah? which also functions as a tag in the Chinese dialect (Cheung, 1974). In the case of both languages, there is no need for reversal of polarity of tag questions.

The translations given by the Malay subjects and the Chinese subjects, all using either the right form or the particle $a h$ as tag questions, proved to be a result of the process of interference in which the feature of non-reversal in polarity in the first language is applied to the second language, in line with Mackey's (1970) definition. According to Nabahan (as cited in Win Listyaningrum Arifin, 2011), interference occurs when typical utterances of the mother tongue appear when using another language. Additionally, the result also indicates that the respondents were not aware of the special function that a constant polarity tag question takes on which is to hint at sarcasm. Thus, it is evident that there is a decrease in the number of functions that a tag question can take on when used by the respondents.

The reason behind these confined structures can be better understood by analysing the sentence structure of the respondents' mother tongue. As previously mentioned, in Malay, there is no polarity rule in its tag question formation (Kader, 1981) and there are only two tags utilised, which are, bukan? and tidak?. The tag, bukan, was regarded the only tag used in Malay by both Kader (1981) and Crewe (1979). In this study, it is observed that the Malay subjects had treated the tag tidak or tak the same way as they did the tag bukan in the translation task, as shown in the examples below:

\section{Hari ni Mira pergi kelas tak? \\ Today Mira's going to class, is it? \\ Hari ni Mira pergi kelas tak? \\ Today Mira's going to class, ah?}

In Cantonese, however, the only question tag utilised is ah? as asserted by Cheung (1974). He also stated that there is no need for reversal of polarity in Cantonese tag question formation. Malaysian Tamil speakers, on the other hand, are evidently influenced by the formation of questions in Malay and Chinese, as in Tamil, a type of polarity reversal does exist in question tags formation - there should not be a double negative in the structure of a question tag (e.g., I'm pretty, not? / I'm ugly, not?). These subjects, including Tamil speakers, might have therefore presumed that a similar rule existed in the formation of the English question tag. Thus, through simplification, the subjects have arrived at the tag question structure 
that utilised only these four question tags, isn't it?, is it?, right and the particle $a h$, as asserted by Norrizan Razali (1995) based on her previous study.

As regards wh-interrogatives formation, the non-existence of auxiliary verbs and lack of the verb tense or tensing and inflections, in Malay and Cantonese, as compared to English, has a big influence over formation of questions by the subjects - in line with Gupta's (1994) and Crewe's (1979) claims of an existent interference from both languages in ME's sentence structure. Malay does not have the category of tense - as stated by Asmah Haji Omar (1993). She further explains that the aspect verbs sudah, telah, pernah (the three being indicators of completed action), masih, sedang (both indicating action in process), belum, and akan (both indicating action not yet executed), however, do relate to time but they need not necessarily in their usage be linked to the time the action has been executed, or in the process of execution, or waiting to be executed. The use of such aspect verbs are evident in the Malay subjects' responses in the translation task during the interview sessions. As does in the Chinese subjects responses. Examples are as follows:

In Malay:

Where did he eat?

Dia makan kat mana [semalam/tadi]?

He eat where yesterday/ just now?

Where is he eating?

Dia [tengah] makan kat mana?

$\mathrm{He}$ in the midst of eat where?

In Cantonese:

Where did he eat?

[Tao xin] kui hai pin tou sik yeh?

Just now, where he eat?

Where is he eating?

[Yika] kui hai pin tou sik yeh?

Now, where he eat?

In the second example of Malay usage, the subject is found to use the aspect verb tengah which is a more colloquial equivalent of masih or sedang - to denote action in process. Although in actuality the question word (equivalent to wh-word in $\mathrm{SBE}$ ) in Malay interrogatives can be positioned at either the beginning or the end of the structure - there is a tendency for the subjects to position it at the end of each interrogative. Question words are not commonly fronted, except for why and how and this post-position of interrogatives is claimed to also be affected by the Malay language (Samida \& Takahashi, n.d.). Thus, it can be said that both these features as well as the lack of auxiliary in Malay influence the subjects' formation of English interrogatives.

Tamil, however, despite it not having the auxiliary system, is found to be a highly inflected language - having verb tense as well as number markers. Wh- 
interrogatives in Tamil are introduced by a pronoun, instead of an equivalent of a wh-word in Tamil - followed by a conjugated verb. The following is an example from the translation task for the sentence where did he eat?:

\section{Avvaru engge sapetharu? \\ He where ate? \\ (Where did he eat?)}

The study done by Govindan and Pillai (2009), found that even their respondents who were dominant speakers of English used similar structures of wh-interrogatives in informal settings. On top of the omission of auxiliary, the past tense of verbs was used as in What you ate for recess? This means that the tense system is not unknown to Tamil speakers, making the language, to a certain extent, more similar to English than Malay and Cantonese. In light of the two possible structures of a preand mid-position of the wh-question word, it can be said that the Tamil speakers were also influenced by wh-interrogative structures in their mother tongue. It is worth noting that the mid-position of question word does not occur for standard Malay interrogatives thus it is assumed that this feature is characteristic of Tamil interrogative structure. With limited data on such a structure, it could not yet be determined whether it is prevalent in the English usage of Tamil speakers thus an argument will not be put forward. Their formation of tag questions, however, remains similar to that of their Malay and Chinese counterparts. At least for tag questions, it can be concluded that the Indian respondents were immensely influenced by the structure of the more dominant languages which are Malay and Chinese. Thus, on the whole, interference at the grammatical level is found to play a major part in determining the forms of interrogatives and tag questions used by young Malaysian speakers of English.

\section{Conclusion}

The study showed that the usage of various distinctive forms and features of ME questions is linked to the domains of conversation and subjects' familiarity with each other. In the more informal domain (i.e., friendship), the frequency of usage of wh-interrogatives and tag questions is higher due to the more natural environment for speech which allows for a free flow of communication strategies and techniques. The study also revealed that mother tongue interference at the grammatical level contributes greatly in determining the structure of $\mathrm{ME}$ interrogatives and question tags as well as the subjects' unvarying use of the rising intonation as regards the latter. This is true in the case of interference from Malay and Cantonese languages. As for Tamil speakers, while they were evidently influenced by their mother tongue in the formation of wh-interrogatives, the results for tag questions may suggest that they were influenced by the more dominant national language, Malay or the alternative, Cantonese. As a result of this interference and other processes in second language acquisition, the ME tag question structure used is more often than not confined to the four forms which were asserted by Norrizan Razali (1995) whilst 
both the structure of wh and polar interrogatives experience reduction in the system of tense, auxiliary and operator.

\section{References}

Alsagoff, L., Bao, Z., \& Wee, L. (1998). Why you talk like that?: The pragmatics of a why construction in Singapore English. English World-Wide, 19(2), 14, 247-260.

Asmah Haji Omar. (1993). Language and society in Malaysia. Kuala Lumpur, Malaysia: Dewan Bahasa dan Pustaka.

Baskaran, L. (1987). Aspects of Malaysian English syntax. Unpublished doctoral thesis, University of London, United Kingdom.

Baskaran, L. (1994). The Malaysian English mosaic. English Today, 37(10), 27-32.

Baskaran, L. (2004). Malaysian English: Morphology and syntax. In B. Kortmann, K. Burridge, R., Mesthrie, E. W. Schneider, \& C. Upton (Eds.), A handbook of varieties of English (pp. 374-90). Berlin, Germany: Mouton de Gruyter.

Borlongan, A. M. (2008). Tag questions in Philippine English. Philippine Journal of Linguistics, 39(1), Retrieved from http://ejournals.ph?index.php?journal= hsjakgdfeuwbrenmmzvrio\&page=article\&op=view\&path[]=71\&path[]=75

Cheung, Y. S. (1974). Negative questions in Chinese. Journal of Chinese Linguistics, 2(3), 325-339.

Cole, P., \& Hermon, G. (1998). The typology of wh-movement and wh-questions in Malay. Syntax, 1(3), 221-258. Retrieved from http://citeseerx.ist.psu.edu/ viewdoc/download?doi=10.1.1.79.8111\&rep=rep1\&type=pdf

Crewe, W. (1979). Singapore English and standard English: Exercise in awareness. Singapore: Eastern Universities Press.

Govindan, I., \& Pillai, S. (2009). English question forms used by young Malaysian Indians. The English Teacher, 38, 74-94.

Gupta, A. F. (1994). Singapore colloquial English (Singlish). Retrieved from http://www. une.edu.au/langnet/singlish

Halliday, M. A. K., McIntosh, A., \& Strevens, P. (1964). The linguistic sciences and language teaching. London, UK: Longmans.

Kader, B. H. M. (1981). The syntax of Malay interrogatives. Kuala Lumpur, Malaysia: Dewan Bahasa and Pustaka.

Kow, Y. C. (1995). It is a tag question, isn't it? The English Teacher, XXIV. Retrieved from http://www.melta.org.my/ET/1995/main5.html

Lee, S. K. (1998). Manglish. Petaling Jaya, Malaysia: Pelanduk Publications.

Lim, C. L. (2009, February 13). What's the question again? The Star. Retrieved from http://www.thestar.com.my/

Low, E., \& Brown, A. (2005). English in Singapore: An introduction. Singapore: McGraw-Hill.

Mackey, W. P. (1970). The description of bilingualism. In J. Fishman (Ed.), Readings in the sociology of language. The Hague, Paris: Mouton de Gruyter.

Norrizan Razali. (1995). Tagging it the Malaysian style. The English Teacher, XXIV. Retrieved from http://www.melta.org.my/ET/1995/main5.html 
Pillai, S. (2006). Malaysian English as a first language. In M. K. David (Ed.), Language choices and discourse of Malaysian families: Case studies in KL, Malaysia (pp. 61-75). Petaling Jaya, Malaysia: Strategic Information Research Development Centre.

Platt, J., \& Weber, H. (1980). English in Singapore and Malaysia. Kuala Lumpur, Malaysia: Oxford University Press.

Samida, D., \& Takahashi, J. (n.d.). World Englishes (3): Malaysian and Philippine English. Retrieved from http://libro.do-bunkyodai.ac.jp/research /pdf/treatises/14/07 -samida.pdf

Sato, Y. (2011). Wh-Questions in colloquial Singapore English: Syntactic evidence for the Malay substrate hypothesis. Retrieved from http://ling.auf.net/lingbuzz/001234

Ting, S. H., Mahanita Mahadhir, \& Chang, S. L. (2010) Grammatical errors in spoken English of university students in oral communication course. GEMA Online Journal of Language Studies, 10(1), 53-70.

Win Listyaningrum Arifin. (2011). Interference: Its role in the target language mastery to Indonesian learners. Register, 4(1), 99-115.

Wong, I. (1983). Simplification features in the structure of colloquial Malaysian English, In R. B. Noss (Ed.), Varieties of English in South East Asia (pp. 125149). Singapore: Singapore University Press. 